\title{
Changes in clinical features in Henoch-Schönlein purpura during three decades: an observational study at a single hospital in Korea
}

\author{
Jung-Woo Rhim ${ }^{1,2} \cdot$ Yoon-Tae Lee ${ }^{1} \cdot$ Hyun-Mi Kang ${ }^{1,2} \cdot$ Jin-Soon Suh $^{1} \cdot$ Kyung-Yil Lee $^{1,2}$ (D)
}

Received: 5 April 2019 / Revised: 22 May 2019 / Accepted: 28 May 2019 / Published online: 8 June 2019

(C) International League of Associations for Rheumatology (ILAR) 2019

\begin{abstract}
Objective It is unknown whether epidemiological or clinical characteristics of Henoch-Schönlein purpura (HSP) have changed over time. This study aimed at evaluating the epidemiological and clinical changes of HSP during 3 decades.

Methods We retrospectively analyzed the data of 515 children with HSP (0-15 years of age) between 1987 and 2015 . We compared the two HSP patient groups: those admitted from 1987 to 1996 (group A, 238 cases) and those admitted from 2006 to 2015 (group B, 98 cases), apart a decade.

Results In total 515 patients, the mean age was $6.5 \pm 3.0$ years and the male-to-female ratio was 1.2:1 (278:237). The age distribution showed a peak at age 5 with a bell-shaped distribution pattern. The annual number of cases varied in each year with a trend of reduced cases in the recent decade. There were less cases during the summer season. Purpura, gastrointestinal involvement, joint involvement, and renal involvement were found in 100\%, 56\%, 38\%, and 18\% of the patients, respectively. In comparison between the two groups, there were similar findings in mean age, age distribution, and seasonal distribution. However, the hospitalization stay was longer, and the proportion of recurrent cases (14 cases vs. 0 case) and proteinuria (15\% vs. $3 \%$ ) were higher in the group A than in the group B.

Conclusions Long-term epidemiologic features of HSP were similar to those in other countries. Clinical manifestations of HSP showed a trend towards a less severe clinical phenotype over time in Deajeon, Korea.

\section{Key Points}

- It is unknown whether epidemiological and clinical traits of Henoch-Schönlein purpura (HSP) have changed over time.

- We reported that clinical manifestations of HSP have changed to milder phenotype through a long-term observation of three decades at a single hospital in Daejeon, South Korea.

- Clinical phenotype of infection-related diseases, including HSP, may be changed over time, and the etiology and the reason of clinical changes over time remain to be solved.
\end{abstract}

Keywords Children $\cdot$ Epidemiology $\cdot$ Etiology $\cdot$ Henoch-Schönlein purpura $\cdot$ Symptom

\section{Introduction}

Electronic supplementary material The online version of this article (https://doi.org/10.1007/s10067-019-04628-9) contains supplementary material, which is available to authorized users.

Kyung-Yil Lee

leekyungyil@ catholic.ac.kr

1 Departments of Pediatrics, College of Medicine, The Catholic University of Korea, Seoul, Republic of Korea

2 Department of Pediatrics, The Catholic University of Korea Deajeon St. Mary's Hospital, 64 Daeheung-ro, Jung-gu, Daejeon 34943, Republic of Korea
Henoch-Schönlein purpura (HSP) is a childhood systemic vasculitis which is characterized by purpura, abdominal pain, arthritis, and renal involvement, which can also affect adults [1]. Since the first report of HSP in medical literature during the early nineteenth century, this disease has now been observed throughout the world [2]. Majority of the affected patients recover within 1 month; however, some patients with severe renal involvement progress to end-stage renal disease [3].

The etiology and pathogenesis of HSP remain unknown. It has been suggested that infection caused by various pathogens, including streptococci and viruses, may be associated with the 
disease onset [1-3]. Therefore, HSP can be regarded as an infection-related immune-mediated disease that is triggered by the insults from unknown pathogen infections. It has also been suggested that environmental factors, such as lifestyle and economic status, and genetic factors may be associated with the incidence of the disease [4]. However, the prevalence and clinical manifestation of the disease may vary in different ethnic groups and at certain time periods [5-9].

Infection-related immune-mediated diseases such as acute rheumatic fever and acute poststreptococcal glomerulonephritis (APSGN) have been reported to present milder phenotypes and have become rare diseases in Korea over time [10, 11]. Thus, it can be hypothesized that epidemiological and clinical traits of HSP have changed over time. Although numerous studies on HSP have been performed, long-term studies regarding changes in epidemiology or clinical manifestation are rare.

In this study, we aimed to evaluate changes in epidemiological and clinical features of HSP by comparing the clinical manifestation between recently diagnosed HSP patients and HSP patients diagnosed in the past in Daejeon, South Korea.

\section{Patients and methods}

This study was a retrospective study conducted at the Department of Pediatrics, The Catholic University of Korea Daejeon St. Mary's Hospital, a secondary referral hospital performing primary care for patients with HSP.

The subjects of this study were consecutive unselected patients that were admitted and diagnosed with HSP from January 1987 to December 2015. Data from patients diagnosed during 1987-2003 $(n=395)$ were obtained from preliminary data from a previously published study [12]. From 2004 to $2015(n=120)$, the medical records of the patients were reviewed and the same study parameters from the preliminary data were collected.

All patients were clinically diagnosed with HSP using the following criteria; subjects had palpable purpura with at least one of the following symptoms or signs: (1) gastrointestinal involvement such as abdominal pain and/or other gastroenterological symptoms, or (2) joint involvement such as arthritis and/or other associated symptoms such as arthralgia and soft tissue swelling, or (3) renal involvement such as hematuria and/or proteinuria in urinalysis.

The subjects also satisfied the diagnostic criteria of the European League Against Rheumatism/Paediatric Rheumatology European Society published in 2006 [13]. In this study, patients readmitted within 1 or 2 months after the first attack were excluded and only the clinical data obtained from the first admission was included in the analysis. Recurrent cases of HSP, occurring $\geq 6$ months after the first episode, were included as subjects for epidemiological and clinical analysis (18 cases). During the study period, the population in the city that the hospital was located in had increased from approximately 1 million to 1.5 million. Together with economic growth and decreasing birth rates in Korea, it is possible that an increase in concerns of parents or guardians regarding their children's health, as well as hospital accessibility, has led to more frequent hospital visits in the recent decade. During the study period, there have been no significant changes in the accessibility of our institution in the city, referral practices in the primary clinics, and diagnosis and treatment policies in the pediatric department.

The following parameters were investigated: demographic data including patients' age and gender, hospitalization date, duration of admission, and three clinical manifestations, and gastrointestinal involvement, joint involvement, and renal involvement. Hematuria was defined as 10 or more red blood cells per high-power field in a microscopic urinalysis, and proteinuria was defined as $>4 \mathrm{mg} / \mathrm{m}^{2} / \mathrm{h}$ or protein/creatinine ratio in urine spot $>0.2$. Renal involvement was defined as the presence of hematuria or proteinuria or both.

Because the aim of this study was at recognizing any distinct changes in epidemiological and clinical features of HSP over time, we compared patient groups from two time periods: those admitted during the first 10 years of study, from 1987 to $1996(n=238)$, versus the last 10 years, from 2006 to 2015 $(n=98)$, the two groups separated by a decade (Fig. 1).

\section{Statistical analysis}

The statistical analysis package used was SPSS Windows 18.0. Cross-tabulation analysis, chi-square test, and independent sample $t$ test were used to analyze the response distribution of each item according to the year classification variable. Statistical significance of the collected data was defined as a $P$ value of 0.05 or less.

\section{Results}

\section{Epidemiological characteristics of total HSP patients}

During the 29-year study period, from January 1987 to December 2015, a total of 515 patients were diagnosed and treated for HSP. The mean age of the patients was $6.5 \pm$ 3.0 years, and male-to-female ratio was 1.2:1. The peak prevalence of patients with HSP was 5 years of age $(n=81,16 \%)$, and $84 \%(n=433)$ of the patients were between 3 to 10 years old. The age distribution showed a bell-shaped pattern with a peak at age 5 (Fig. 2). The annual number of cases varied, ranging from 3 cases in 2007 to 38 cases in 1993. No cyclic outbreak portraying an infectious disease epidemic was observed, such as Mycoplasma pneumonia infection and measles in the pre-vaccine era. A trend of reduced number of 
Fig. 1 Flow diagram of the patient selection in this study
Children diagnosed with Henoch-Schönlein purpura (HSP) (January 1987- December 2015)

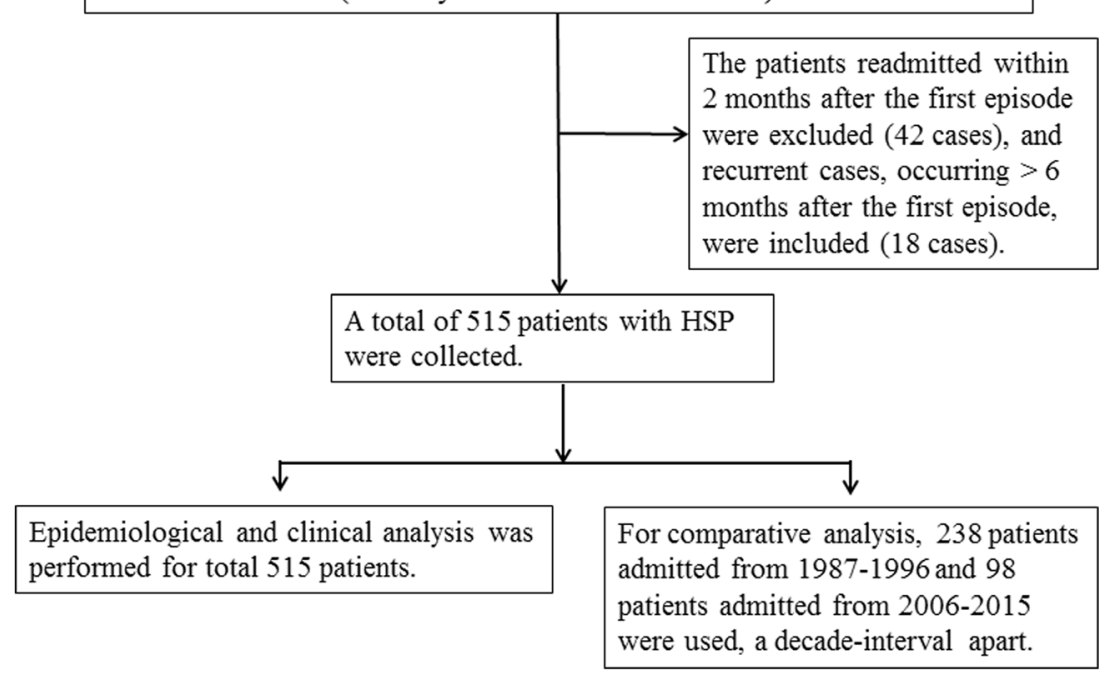

diagnosed cases per year was seen in the recent decade (Fig. 3). In terms of monthly number of cases, there were a steady number of patients diagnosed throughout a year. The highest number of patients was diagnosed in March (67/515, 13\%), and the lowest in August (19/515, 4\%). Overall, the peak prevalence was observed during spring (Mar. to May, $n=160,31 \%$ ), followed by autumn (Sep. to Nov., $n=150$, $29 \%$ ) and winter (Dec. to Feb., $n=135,26 \%$ ), and the lowest prevalence seen in the summer $(n=70,14 \%)$ (Fig. 4).

\section{Clinical features of total HSP patients}

Of the total 515 patients, purpura was observed in $100 \%$, gastrointestinal symptoms in 56\% $(n=288)$, joint involvement in 38\% ( $n=161)$, and renal involvement in $18 \%(n=$ 92) of the patients. Of the patients with renal involvement, both hematuria and proteinuria were observed in 49 cases
(10\%), isolated hematuria in 33 cases $(6 \%)$, and isolated proteinuria in 10 cases (2\%). A total 35 patients were readmitted within 2 months after the first episode, and among them, 7 were readmitted twice. There were 18 recurrent cases that presented after 6 months following the first episode (ranging from 6 to 48 months, mean $22.8 \pm 13$ months), and 2 cases had 3 recurrences. In the previous study of HSP patients during 1987 to 2003 [12], there were 4 cases of nephrotic syndrome and 2 cases of nephritic syndrome; however, during 2004 to 2015 , there was only 1 case of nephritic syndrome.

\section{Epidemiological and clinical comparison between the 1987-1996 group and the 2006-2015 group}

Upon epidemiological comparison of the two groups based on the period of diagnosis, the 1987-1996 group $(n=238)$ and
Fig. 2 Age distribution of patients with HSP $(n=515)$

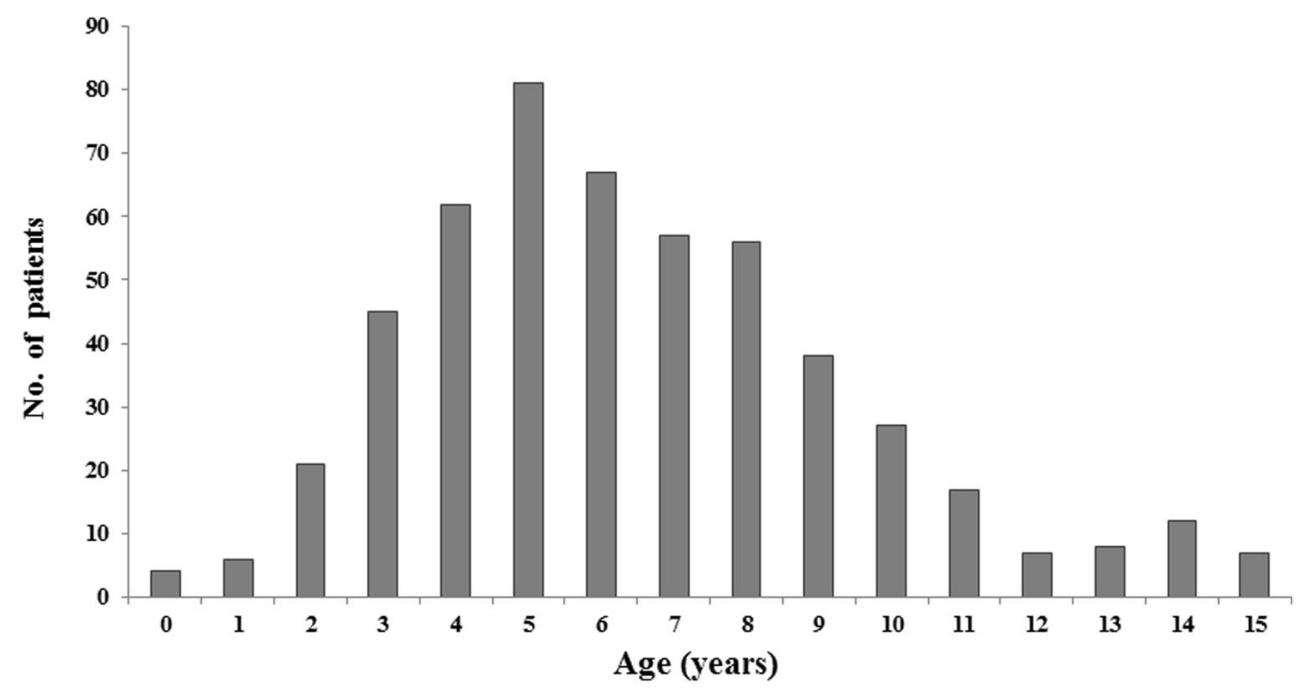


Fig. 3 Annual cases of HSP from 1987 to 2015

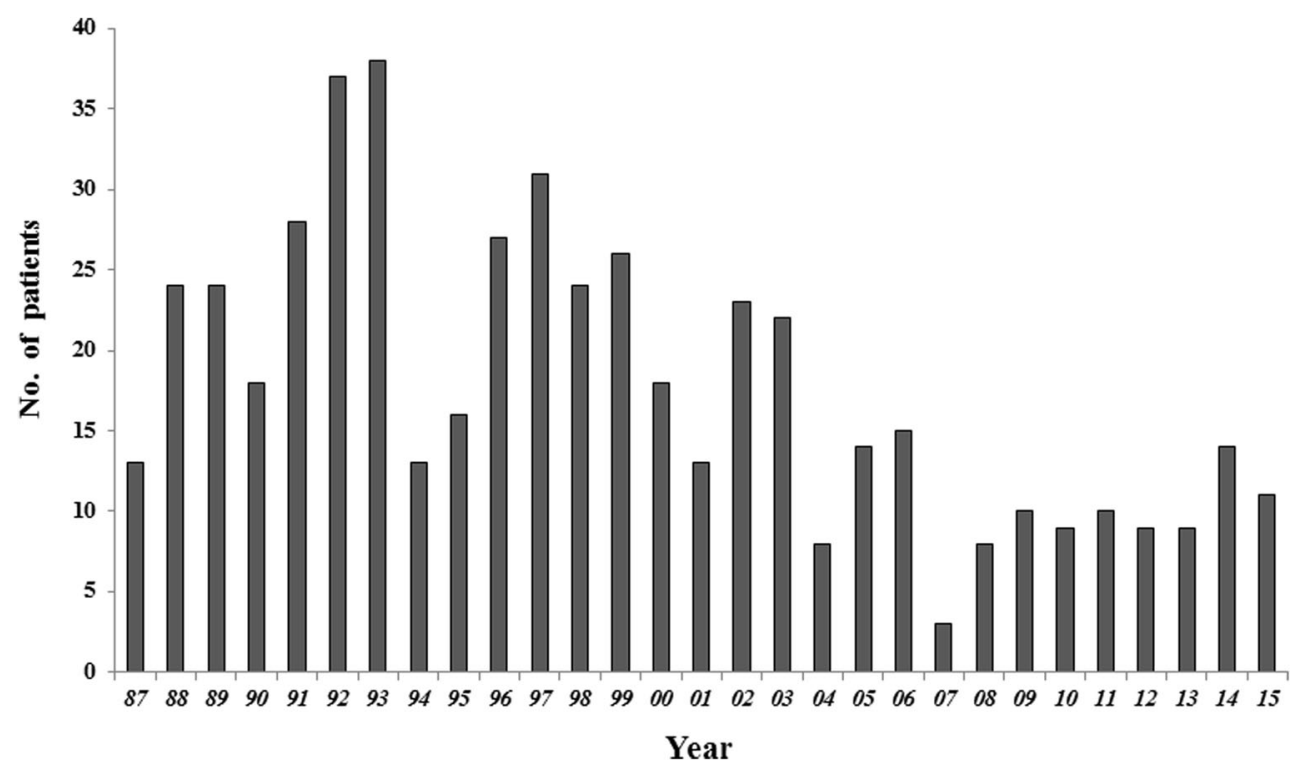

the 2006-2015 group ( $n=98)$, there was no difference in the mean age of the patients (6.9 years vs. 6.2 years, $P=0.098)$ and the age distribution showed similar patterns (Fig. 5). Also, monthly and seasonal distribution also had similar patterns between both groups (Fig. 6). In the comparison of clinical features, there were no differences in the rates of gastrointestinal, joint, and renal involvements between the two groups. However, there were significant differences in hospitalization stay (10.2 days vs. 6.4 days, $P<0.001$ ), recurrent cases (14 cases vs. 0 case, $P<0.001)$, and proteinuria ( $15 \%$ vs. $3 \%, P=$ 0.003 ) between the groups (Table 1).

\section{Discussion}

Since the first report of HSP in medical literature during the early nineteenth century in Europe, HSP has shown similar epidemiological characteristics in the populations, affecting children mainly between 3 to 10 years of age with male predominance. The age distribution has been reported to be a bell-shaped pattern with peak cases at ages 5 to 6 years old. Also, it occurs with some fluctuation in the number of annual cases without a cyclic epidemic and a decrease during the summer months [14-22]. However, the incidence rate of HSP has been reported to differ in various ethnic groups and there have been studies showing a higher prevalence in Western countries compared with African or Middle East Asian countries at a given period [5-8]. In the present study, we found that the epidemiologic characteristics of HSP in our city were consistent compared with clinical studies from other countries as well as Korea, regardless of the study period [14-22]. Furthermore, epidemiological data in both periods, including age distribution and seasonal variation, were similar. A recent nationwide population-based study in Korea (2006-
Fig. 4 Monthly or seasonal distribution of patients

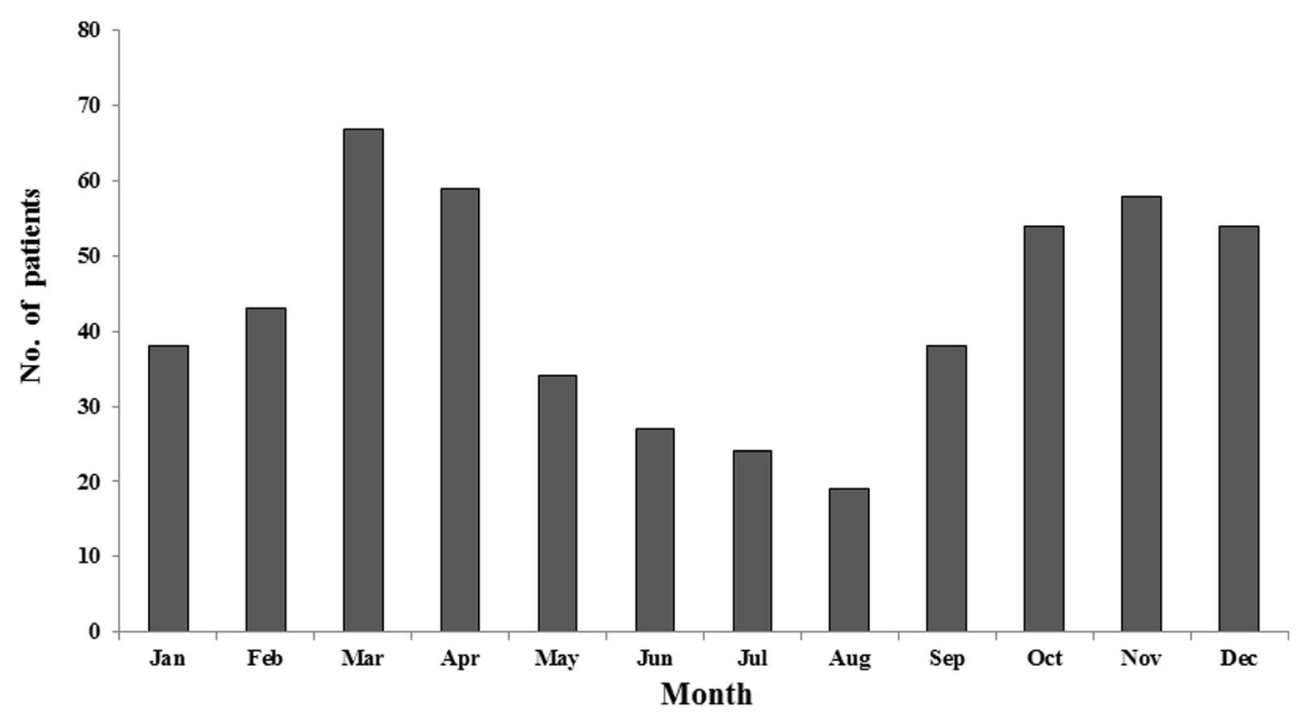


Fig. 5 Age distribution of the 1987-1996 group and the 20062015 group

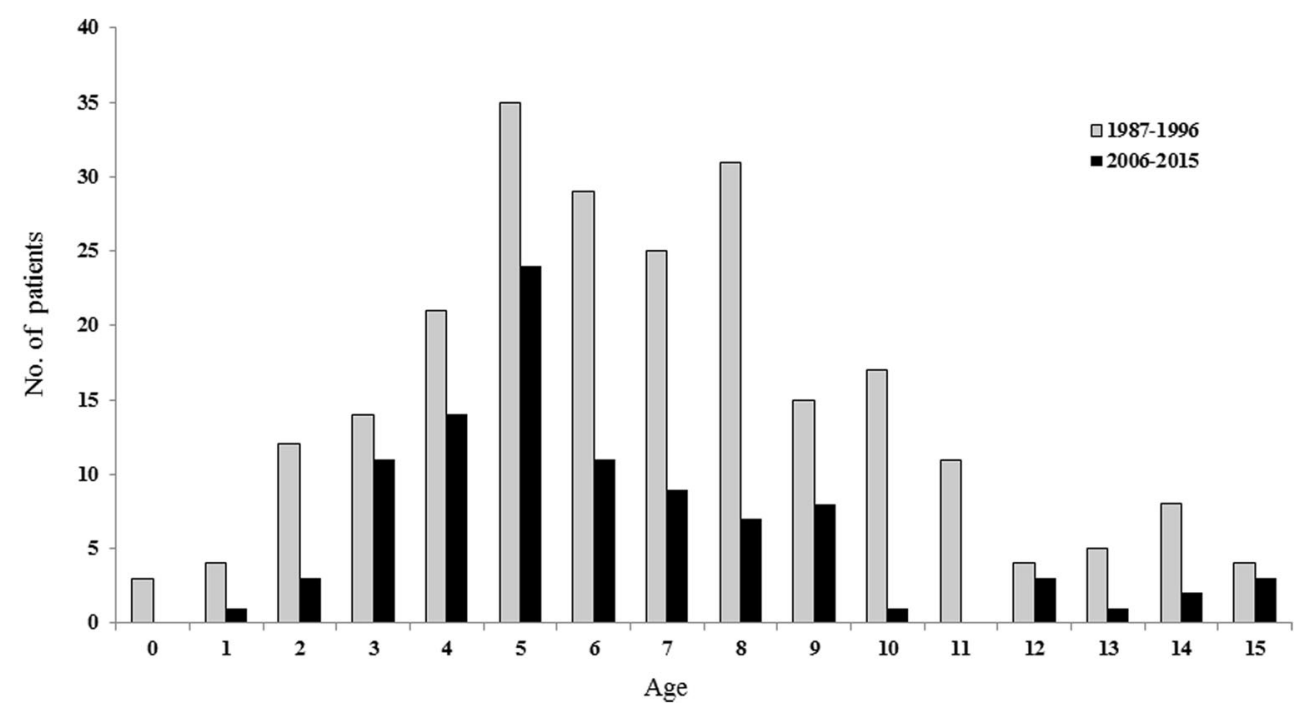

2015) also reported similar age distribution and seasonal occurrence to our results [22]. However, the number of cases diagnosed in the recent decade has decreased to less than a half of that compared with the past decade.

The clinical and epidemiological characteristic of HSP may aid to hypothesize the etiological agent(s) of the disease. The age distribution pattern of HSP was similar to childhood common infectious diseases such as enterovirus aseptic meningitis, 2009 H1N1 pandemic influenza, or Mycoplasma pneumoniae pneumonia in Korea [23-25], suggesting that younger children may have less opportunity to have contact with the pathogens, whereas majority of older children and adults may have immunity or tolerability to the pathogens. However, it is unlikely that HSP is associated with these kinds of common infectious pathogens, because of the different epidemiological characteristics, including no cyclic epidemics and seasonal predilection like aseptic meningitis or influenza. Also, it is possible that there may be different clinical manifestations across ethnic groups as shown in this study. Recently, the breakdown of collaborative relationship between normal flora and the host, termed dysbiosis, has been reported in HSP as well as in other acute or chronic infection-related immune-mediated diseases including Kawasaki disease (KD) and juvenile idiopathic arthritis [26-28]. Microbiota differs across ethnic groups with different cultural environments and can be changed due to age, diets, antibiotic use, and possibly genetic factors [29, 30]. Many studies have reported that genetic variations, including HLA loci, may be associated with susceptibility and/or severity of HSP [4, 31] On the other hand, it is well known that some colonized species in normal flora can cause infectious diseases such as acute pyelonephritis caused by various enteric species, including Escherichia coli, or postinfectious immune-mediated diseases when they invade and induce immune reactions [32, 33]. Patients who do not have immunity or tolerability to HSP
Fig. 6 Monthly cases of the 1987-1996 group and the 20062015 group

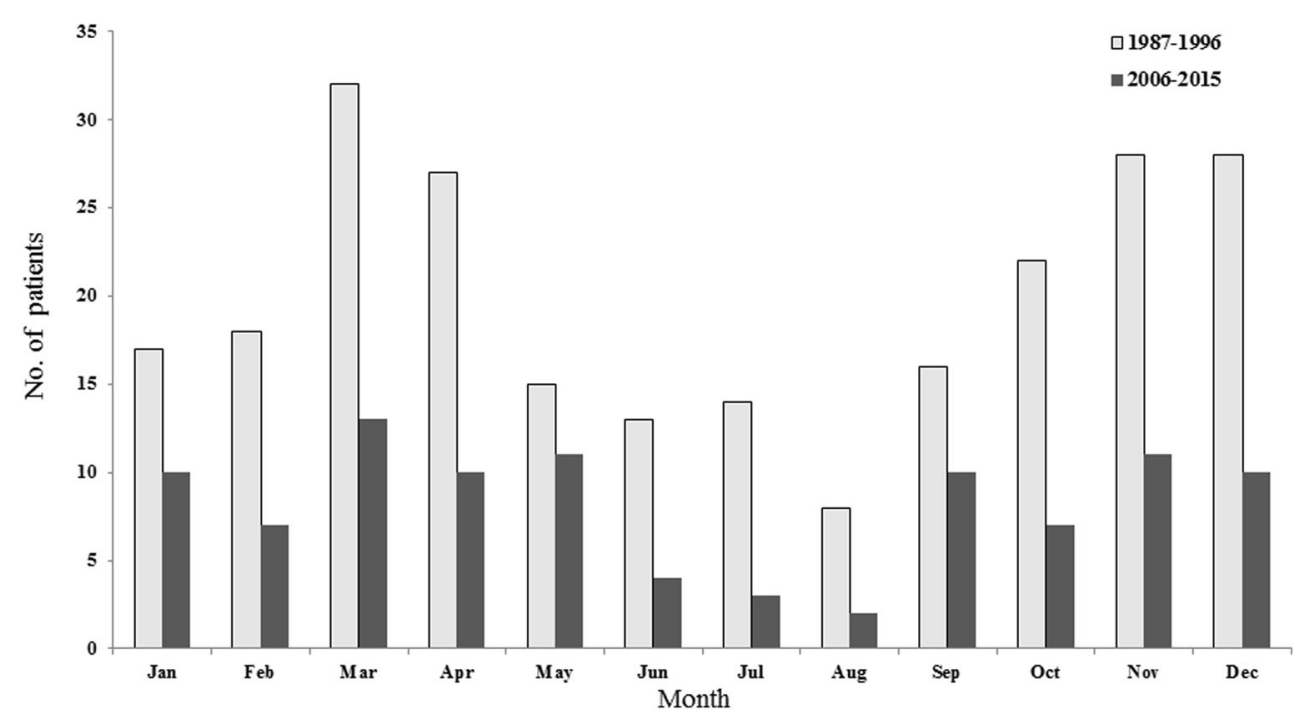


Table 1 Clinical features of total patients, those admitted from 1987 to $1996,1997-2005$, and 2006-2015

\begin{tabular}{llllll}
\hline Age groups & $\begin{array}{l}\text { Total } \\
(n=515)\end{array}$ & $\begin{array}{l}1987-1996 \\
(n=238)\end{array}$ & $\begin{array}{l}1997-2005 \\
(n=179)\end{array}$ & $\begin{array}{l}2006-2015 \\
(n=98)\end{array}$ & $P^{*}$ \\
\hline Age (year) & $6.5 \pm 3.0$ & $6.9 \pm 3.3$ & $6.2 \pm 2.6$ & $6.2 \pm 3.2$ & 0.95 \\
Male:female & $278: 237$ & $133: 105$ & $97: 82$ & $49: 49$ & 0.37 \\
Hospitalization (day) & $8.8 \pm 5.4$ & $10.1 \pm 6.1$ & $8.4 \pm 5.1$ & $6.4 \pm 2.7$ & $<0.001$ \\
Recurrent case, $n(\%)$ & $18(3)$ & $14(6)$ & $4(2)$ & $0(0)$ & $<0.001$ \\
Purpura & $515(100)$ & $238(100)$ & $179(100)$ & $98(100)$ & \\
GI involvement & $288(56)$ & $127(53)$ & $98(55)$ & $63(64)$ & 0.08 \\
Joint & $195(38)$ & $85(36)$ & $66(37)$ & $44(45)$ & 0.25 \\
Renal involvement & $92(18)$ & $51(21)$ & $27(15)$ & $14(14)$ & 0.15 \\
$\quad$ Hematuria & $82(16)$ & $46(19)$ & $22(12)$ & $14(14)$ & 0.29 \\
Proteinuria & $59(12)$ & $35(15)$ & $21(12)$ & $3(3)$ & 0.003 \\
\hline
\end{tabular}

Data were obtained at presentation of the patients

*Statistical analysis between the 1987-1996 and the 2006-2015 pathogens or those who have an improper immune system may elicit the disease when the colonized microbials invade and induce immune reactions in the host [34].

In HSP, gastrointestinal involvement has been reported in 34 to $75 \%$ of the patients, joint involvement $36-82 \%$, and renal involvement 26-54\% [5-9, 14-22]. In the present study, gastrointestinal, joint, and renal involvements were seen as $56 \%, 38 \%$, and $18 \%$, respectively. Renal complication is the major determinant of poor prognosis. In the present study, the rate of renal involvement was lower and less severe than in previous reports. Renal complications can occur after purpura subsides, and patients with severe renal involvement are usually transferred to pediatric nephrologists, having a higher selection bias in study groups. Varying HSP clinical manifestations and treatment modalities in different hospitals may result in variable clinical outcome data $[3,35]$. Although the rates of renal involvement were similar in the 2 groups, only 3 patients had proteinuria in the recent decade. Generally, proteinuria depicts a more severe extent of renal injury in HSP nephritis. In the recent decade, other clinical parameters also reflected a trend towards a milder phenotype; longer hospitalization was noted in the early period group, which is likely associated with the number of patients with severe renal involvement. A part of HSP patients (18 cases) showed recurrences after the initial manifestation of the disease, and similar finding has been noted in KD. Some investigators reported that recurrent cases of HSP and KD had more severe clinical symptoms and a higher risk of complications [36, 37]. Changes in clinical severity of the disease have been observed in other diseases. For example, scarlet fever caused by group A streptococci (GAS) was a severe disease with fatal cases in children during the pre-antibiotic era. The severity and incidence of scarlet fever and its complications, acute rheumatic fever and APSGN, have become milder and lower over time in Korea as well as in developed countries [10, 11, 38].
Because GAS carriers in healthy children have been observed with higher prevalence in the populations [39], it is possible that GAS strains may be evolving to be part of the normal flora in the upper respiratory tract. KD has also been reported to be less severe both in clinical and laboratory features without changes in demographic characteristics, compared with studies from two decades ago in Korea [40]. The prevalence and clinical manifestation of acute infection-related immunemediated diseases, such as acute rheumatic fever, APSGN, $\mathrm{KD}$, and HSP, may change over time. This change may be associated with changes in the socioeconomic development and pathogen-host relationship, such as change of herd immunity against pathogens or change of the pathogens in microbiota, in the populations.

There are some limitations to this retrospective study. Because of the long-term duration of this study, medical records prior to 2004 were not available, therefore making it difficult to analyze clinical parameters such as the severity and duration of abdominal pain, arthritis, proteinuria, and other complications. Since the data in this study is from a single center and there had been no nationwide epidemical data in Korea during the study period, we could not confirm that the decreased number of patients in the recent decade was nationwide. However, majority of diagnosed patients with HSP were received admission care and patients who had only purpura might rarely refer to our institution.

In conclusion, epidemiological features of HSP were similar to those of other regions in Korea and other countries but a decrease in the number of cases was noted in the recent decade compared with the past decade. Clinical parameters such as hospitalization stay, presence of proteinuria, and recurrence rates were lower in the recent decade. Our study suggests that HSP may be becoming a trend towards a milder clinical course in Korea. 
Acknowledgments We thank Sun-Mi Choi, Eun-Ae Yang, Ji-Yoon Han, and other colleagues for patient care and data collection during the study period.

\section{Compliance with ethical standards}

At the time of admission, the written informed consents were obtained from the parents/caregivers of all children for the medical records to be used in this study. The study was approved by the Institutional Review Board of The Catholic University of Korea Daejeon St. Mary's Hospital (DC17RESI0054).

Disclosures None.

\section{References}

1. Ardoin SP, Fels E (2017) Vasculitis syndromes. In: Kliegman RM, Stanton BF, Geme S III, Schor NF, Behrman RE, Jenson HB et al (eds) Nelson textbook of pediatrics. Elsevier, New Delhi, pp 12151218

2. Saulsbury FT (2010) Henoch-Schönlein purpura. Curr Opin Rheumatol 22:598-602. https://doi.org/10.1097/BOR. 0b013e32833af608

3. Davin JC, Coppo R (2014) Henoch-Schönlein purpura nephritis in children. Nat Rev Nephrol 10:563-573. https://doi.org/10.1038/ nrneph.2014.126

4. López-Mejías R, Castañeda S, Genre F, Remuzgo-Martínez S, Carmona FD, Llorca J, Blanco R, Martín J, González-Gay MA (2018) Genetics of immunoglobulin-A vasculitis (HenochSchönlein purpura): an updated review. Autoimmun Rev 17:301305. https://doi.org/10.1016/j.autrev.2017.11.024

5. Coovadia HM (1982) Henoch-Schönlein purpura in Black and Indian children in Natal. S Afr Med J 62:433-434

6. Gardner-Medwin JM, Dolezalova P, Cummins C, Southwood TR (2002) Incidence of Henoch-Schönlein purpura, Kawasaki disease, and rare vasculitides in children of different ethnic origins. Lancet 360:1197-1202. https://doi.org/10.1016/S0140-6736(02)11279-7

7. Akl K (2007) Childhood Henoch-Schönlein purpura in Middle East countries. Saudi J Kidney Dis Transpl 18:151-158

8. Singh S, Aulakh R (2010) Kawasaki disease and Henoch Schonlein purpura: changing trends at a tertiary care hospital in North India (1993-2008). Rheumatol Int 30:771-774. https://doi.org/10.1007/ s00296-009-1065-6

9. Calvo-Río V, Loricera J, Mata C, Martín L, Ortiz-Sanjuán F, Alvarez L, González-Vela MC, González-Lamuño D, RuedaGotor J, Fernández-Llaca H, González-López MA, Armesto S, Peiró E, Arias M, González-Gay MA, Blanco R (2014) HenochSchönlein purpura in northern Spain: clinical spectrum of the disease in 417 patients from a single center. Medicine 93:106-113. https://doi.org/10.1097/MD.0000000000000019

10. Quinn RW (1989) Comprehensive review of morbidity and mortality trends for rheumatic fever, streptococcal disease, and scarlet fever: the decline of rheumatic fever. Rev Infect Dis 11:928-953

11. Kuem SW, Hur SM, Youn YS, Rhim JW, Suh JS, Lee KY (2015) Changes in acute poststreptococcal glomerulonephritis: an observation study at a single Korean hospital over two decades. Child Kidney Dis 19:112-117. https://doi.org/10.3339/chikd.2015.19.2. 112

12. Choi SM, Lee KY (2005) Clinico-epidemiologic study of HenochSchönlein purpura in children, 1987 through 2003. Korean J Pediatr 48:174-177

13. Ozen S, Ruperto N, Dillon MJ, Bagga A, Barron K, Davin JC, Kawasaki T, Lindsley C, Petty RE, Prieur AM, Ravelli A, Woo P
(2006) EULAR/PReS endorsed consensus criteria for the classification of childhood vasculitides. Ann Rheum Dis 65:936-941. https://doi.org/10.1136/ard.2005.046300

14. Saulsbury FT (1999) Henoch-Schönlein purpura in children: report of 100 patients and review of the literature. Medicine 8:395-409

15. Trapani S, Micheli A, Grisolia F, Resti M, Chiappini E, Falcini F, de Martino M (2005) Henoch-Schönlein purpura in childhood: epidemiological and clinical analysis of 150 cases over a 5-year period and review of literature. Semin Arthritis Rheum 35:143-153. https://doi.org/10.1016/j.semarthrit.2005.08.007

16. Fretzayas A, Sionti I, Moustaki M, Papadimitriou A, Nicolaidou P (2008) Henoch-Schönlein purpura: a long-term prospective study in Greek children. J Clin Rheumatol 14:324-331. https://doi.org/ 10.1097/RHU.0b013e31817a240a

17. Anil M, Aksu N, Kara OD, Bal A, Anil AB, Yavaşcan O, Un B (2009) Henoch-Schönlein purpura in children from western Turkey: a retrospective analysis of 430 cases. Turk J Pediatr 51: 429-436

18. Calviño MC, Llorca J, García-Porrúa C, Fernández-Iglesias JL, Rodriguez-Ledo P, González-Gay MA (2001) Henoch-Schönlein purpura in children from northwestern Spain: a 20-year epidemiologic and clinical study. Medicine 80:279-290

19. Kawasaki Y, Suyama K, Yugeta E, Katayose M, Suzuki S, Sakuma H, Nemoto K, Tsukagoshi A, Nagasawa K, Hosoya M (2010) The incidence and severity of Henoch-Schönlein purpura nephritis over a 22-year period in Fukushima Prefecture, Japan. Int Urol Nephrol 42:1023-1029. https://doi.org/10.1007/s11255-009-9701-3

20. Chen O, Zhu XB, Ren P, Wang YB, Sun RP, Wei DE (2013) HenochSchönlein purpura in children: clinical analysis of 120 cases. Afr Health Sci 13:94-99. https://doi.org/10.4314/ahs.v13i1.26

21. Lee YH, Lee YH, Kim YB, Chung JY (2016) Henoch-Schönlein purpura in children hospitalized at a tertiary hospital during 20042015 in Korea: epidemiology and clinical management. Pediatr Gastroenterol Hepatol Nutr 19:175-185. https://doi.org/10.5223/ pghn.2016.19.3.175

22. Shim JO, Han K, Park S, Kim GH, Ko JS, Chung JY (2018) Tenyear nationwide population-based survey on the characteristics of children with Henoch-Schönlein purpura in Korea. Korean J Med Sci 33:e174. https://doi.org/10.3346/jkms.2018.33.e174

23. Lee KY, Burgner D, Lee HS, Hong JH, Lee MH, Kang JH, Lee BC (2005) The changing epidemiology of pediatric aseptic meningitis in Daejeon, Korea from 1987 to 2003. BMC Infect Dis 5:97. https:// doi.org/10.1186/1471-2334-5-97

24. Rhim JW, Lee KY, Youn YS, Kang JH, Kim JC (2011) Epidemiological and clinical characteristics of childhood pandemic 2009 H1N1 virus infection: an observational cohort study. BMC Infect Dis 11:225. https://doi.org/10.1186/1471-2334-11-225

25. Kim EK, Youn YS, Rhim JW, Shin MS, Kang JH, Lee KY (2015) Epidemiological comparison of three Mycoplasma pneumoniae pneumonia epidemics in a single hospital over 10 years. Korean J Pediatr 58:172-177. https://doi.org/10.3345/kjp.2015.58.5.172

26. Wang X, Zhang L, Wang Y, Liu X, Zhang H, Liu Y, Shen N, Yang J, Gai Z (2018) Gut microbiota dysbiosis is associated with HenochSchönlein Purpura in children. Int Immunopharmacol 58:1-8. https://doi.org/10.1016/j.intimp.2018.03.003

27. Kinumaki A, Sekizuka T, Hamada H, Kato K, Yamashita A, Kuroda M (2015) Characterization of the gut microbiota of Kawasaki disease patients by metagenomic analysis. Front Microbiol 6:824. https://doi.org/10.3389/fmicb.2015.00824

28. Arvonen M, Berntson L, Pokka T, Karttunen TJ, Vähäsalo P, Stoll ML (2016) Gut microbiota-host interactions and juvenile idiopathic arthritis. Pediatr Rheumatol Online J 14:44. https://doi.org/10.1186/ s12969-016-0104-6

29. Dominguez-Bello MG, Blaser MJ, Ley RE, Knight R (2011) Development of the human gastrointestinal microbiota and insights 
from high-throughput sequencing. Gastroenterology 140:17131719. https://doi.org/10.1053/j.gastro.2011.02.011

30. Shamriz O, Mizrahi H, Werbner M, Shoenfeld Y, Avni O, Koren O (2016) Microbiota at the crossroads of autoimmunity. Autoimmun Rev 15:859-869. https://doi.org/10.1016/j.autrev.2016.07.012

31. He X, Yu C, Zhao P, Ding Y, Liang X, Zhao Y, Yue X, Wu Y, Yin W (2013) The genetics of Henoch-Schönlein purpura: a systematic review and meta-analysis. Rheumatol Int 33:1387-1395. https:// doi.org/10.1007/s00296-012-2661-4

32. Lee KY (2016) New insights for febrile urinary tract infection (acute pyelonephritis) in children. Child Kidney Dis 20:37-44. https://doi.org/10.3339/jkspn.2016.20.2.37

33. Nast CC (2012) Infection-related glomerulonephritis: changing demographics and outcomes. Adv Chronic Kidney Dis 19:68-75. https://doi.org/10.1053/j.ackd.2012.02.014

34. Lee KY (2015) A common immunopathogenesis mechanism for infectious diseases: the protein-homeostasis-system hypothesis. Infect Chemother 47:12-26. https://doi.org/10.3947/ic.2015.47.1.12

35. Weiss PF, Klink AJ, Hexem K, Burnham JM, Leonard MB, Keren R, Localio R, Feudtner C (2009) Variation in inpatient therapy and diagnostic evaluation of children with Henoch Schönlein purpura. J Pediatr 155:812-818. https://doi.org/10.1016/j.jpeds.2009.05.030

36. Lei WT, Tsai PL, Chu SH, Kao YH, Lin CY, Fang LC, Shyur SD, Lin YW, Wu SI (2018) Incidence and risk factors for recurrent
Henoch-Schönlein purpura in children from a 16-year nationwide database. Pediatr Rheumatol Online J 16:25. https://doi.org/10. 1186/s12969-018-0247-8

37. Maddox RA, Holman RC, Uehara R, Callinan LS, Guest JL, Schonberger LB, Nakamura Y, Yashiro M, Belay ED (2015) Recurrent Kawasaki disease: USA and Japan. Pediatr Int 57: 1116-1120. https://doi.org/10.1111/ped.12733

38. Markowitz M (1994) Changing epidemiology of group A streptococcal infections. Pediatr Infect Dis J 13:557-560

39. Roberts AL, Connolly KL, Kirse DJ, Evans AK, Poehling KA, Peters TR, Reid SD (2012) Detection of group A streptococcus in tonsils from pediatric patients reveals high rate of asymptomatic streptococcal carriage. BMC Pediatr 12, 3. https://doi.org/10. 1186/1471-2431-12-3

40. Kil HR, Yu JW, Lee SC, Rhim JW, Lee KY (2017) Changes in clinical and laboratory features of Kawasaki disease noted over time in Daejeon. Korea Pediatr Rheumatol Online J 15:60. https://doi. org/10.1186/s12969-017-0192-y

Publisher's note Springer Nature remains neutral with regard to jurisdictional claims in published maps and institutional affiliations. 